\title{
A field study of unstable preferential flow during soil water redistribution
}

\author{
Zhi Wang, ${ }^{1}$ Laosheng Wu, ${ }^{2}$ Thomas Harter, ${ }^{3}$ Jianhang Lu, ${ }^{2}$ and William A. Jury ${ }^{2}$ \\ Received 24 August 2001; revised 24 April 2002; accepted 9 August 2002; published 1 April 2003.
}

[1] Reversal of the matric potential gradient during redistribution of soil water following infiltration has been hypothesized as a cause of preferential flow by inducing a fluid instability at the leading edge of the wetting front. In this paper, we present results of 17 field experiments carried out to quantify the effects of redistribution on preferential flow in nonstructured soils. The experiments were performed in three field soils (Superstition sand, Delhi sand, and Hanford sandy loam) under saturating and nonsaturating water application rates. Water flow patterns were monitored at various times during redistribution with photography using anionic dyes and by intensive core sampling of bromide added during infiltration. The soil surface was either tilled or undisturbed, exposed or covered with a plastic membrane, and the top 20-cm fine layer was either left in place or removed in various treatments. The infiltration water containing tracers was applied continuously and uniformly to the surface of a $2 \times 1.2 \mathrm{~m}^{2}$ field plot using a moving spray system. After the soil received 8 to $20 \mathrm{~cm}$ of water, a trench was dug adjacent to the plot and vertical soil profiles were exposed at different times and positions to visualize the redistribution process. Some profiles were intensively sampled by soil coring along the trench face and analyzed for water content and bromide concentration to quantify the redistribution of water in the wetted zones. The observed two- and threedimensional distribution of the water tracers clearly indicated the development of unstable flow during redistribution in two of the three soil types studied but not in the coarsesttextured Superstition sand. Symptoms of instability included irregularly shaped fingers that tended to become narrower toward their tips, isolated patches, and highly concentrated areas of the tracers indicating signs of converging and intermittent flow. The measured tortuosity of the wetting front was near 1.0 at the end of infiltration, indicating a stable front, but increased significantly during redistribution until finally declining due to the effects of capillary diffusion. Mean finger thicknesses were comparable (about $13 \mathrm{~cm}$ ) in the two soils where instabilities were observed and were found to be consistent with predictions using an equation developed from stability theory. INDEX TERMS: 1829 Hydrology: Groundwater hydrology; 1831 Hydrology: Groundwater quality; 1866 Hydrology: Soil moisture; 1875 Hydrology: Unsaturated zone; KEYWORDS: Field, preferential flow, unstable, finger, redistribution, matric potential gradient

Citation: Wang, Z., L. Wu, T. Harter, J. Lu, and W. A. Jury, A field study of unstable preferential flow during soil water redistribution, Water Resour. Res., 39(4), 1075, doi:10.1029/2001WR000903, 2003.

\section{Introduction}

[2] At one time, preferential flow was believed to occur exclusively in the cracks and crevices of strongly structured soils and rocks, or in biological channels such as worm or root holes. That belief has been dispelled in the last decade through several comprehensive field studies on so-called nonstructured (uniform) soils, which have shown a strong potential for manifesting preferential flow in locations with-

\footnotetext{
${ }^{1}$ Department of Earth and Environmental Sciences, California State University, Fresno, California, USA.

${ }^{2}$ Department of Environmental Sciences, University of California, Riverside, California, USA.

${ }^{3}$ Department of Land, Air, and Water Resources, University of California, Davis, California, USA.
}

Copyright 2003 by the American Geophysical Union. 0043-1397/03/2001WR000903 out apparent structural voids [Kung, 1990; Jury et al., 1986; Ghodrati and Jury, 1992]. In addition, field surveys using dyes or tracers to track the water flow patterns have observed preferential flow in a variety of settings in both uniform and layered profiles [Starr et al, 1978, 1986; Van Ommen et al., 1988; Hendrickx et al., 1993; Flury et al., 1994]. As a consequence, Jury and Flühler [1992] concluded that preferential flow appears to be the rule rather than the exception in the field.

[3] Flury [1996] reviewed all of the published literature on pesticide transport in the field and concluded that preferential flow of even strongly adsorbed compounds was commonly observed in nonstructured soils, particularly loamy textures, without apparent cause. Despite all of the evidence and effort at monitoring, no correlation between local values of soil textural properties and preferential flow in nonstructured field soils has been developed. One reason why preferential flow might occur in nonstructured soils has 
been largely overlooked: instability in the flow field that is not caused exclusively by local permeability variations or heterogeneity [Raats, 1973; Philip, 1975; Parlange and Hill, 1976]. Furthermore, the instability may be a consequence of one of the commonest hydrologic events in porous media: redistribution following the cessation of rainfall or irrigation.

[4] Earlier theoretical analyses of viscous fingering in petroleum engineering [Saffman and Taylor, 1958; Chuoke et al., 1959] and recent derivations in soil physics [Hill and Parlange, 1972; Raats, 1973; Philip, 1975; Parlange and Hill, 1976] showed that instabilities will develop out of perturbations occurring at the wetting front whenever the matric potential behind the front opposes the flow. Redistribution of water following infiltration creates a matric potential reversal, even in homogeneous soil, and therefore any finger that forms will be reinforced and grow. Capillary effects impede this growth to varying degrees, depending on the type of soil, the infiltration rate, and the initial water content [Glass and Nicholl, 1996].

[5] Laboratory validation of unstable flow in homogeneous soils has been demonstrated in Hele-Shaw cells and slab chambers. Diment and Watson [1985] demonstrated that fingering was caused by redistribution of water following cessation of infiltration in dry sands, a conclusion also drawn by Tamai et al. [1987] in an experiment conducted in glass beads using water and silicon oil. However, Diment and Watson's results also showed that redistribution became stable when the initial water content of the soil was increased by only a few percent. Selker et al. [1992] and Wang et al. [1998b] observed fingering during unsaturated flow infiltration in coarse-textured soils, which could have a strongly reversed matric potential gradient behind the front if the rate of infiltration is below the value of the saturated hydraulic conductivity.

[6] Despite a great deal of research, theories of finger formation and propagation have been limited to stability criteria and characterizations of finger diameter and spatial frequency, derived either empirically or by approximate stability analysis. Hill and Parlange [1972] developed a criterion for stability of infiltration using an analysis of gravity-driven flow (no capillary effects) when water is infiltrating into a medium of saturated hydraulic conductivity $K_{s}$ at a flux rate $i$. They concluded that whenever the system flux ratio $F=i / K_{s}$ is less than 1.0 , fingering is expected to occur. Wang et al. [1998c] modified this criterion by including capillary effects in the classic linear stability analysis of petroleum engineering [Chuoke et al., 1959], concluding that infiltration should become unstable over a narrower range of $F$ depending on the water entry value, $h_{w e}$, of the porous medium at the wetting front. Such an analysis produces the relation

$$
\frac{\left|\varepsilon h_{w e}\right|^{3}}{c}<F<|\cos \beta|-\frac{\left|\varepsilon h_{w e}\right|^{3}}{c}
$$

where $\beta$ is the angle of flow with respect to gravity, $\varepsilon$ is the inverse of the specific gravity of the entering fluid $(\varepsilon=$ $\left.\rho_{\text {water }} / \rho\right)$, and $c$ is an experimental constant $(c=175000)$ evaluated from the data of Yao and Hendrickx [1996]. Thus for vertical water infiltration $(\beta=0, \varepsilon=1)$ into a sandy soil with $h_{w e}=-10 \mathrm{~cm}$, the flow should be unstable when $0.0006<F<0.9994$. In contrast, the range for a loam soil with $h_{w e}=-40 \mathrm{~cm}$ is $0.37<F<0.63$. Recent experiments of unsaturated infiltration conducted by Geiger and Durnford [2000] in homogeneous Ottawa Silica Sands have supported the above predictions. These authors also showed that the absolute value of $h_{w e}$ increased with initial water content and the fineness of the soil texture.

[7] Stability analysis of the flow equation at the wetting front has revealed that unstable flow fingers in nonstructured soil have a characteristic width and spatial frequency or wavelength [Saffman and Taylor, 1958; Chuoke et al., 1959; Philip, 1975]. This might explain why traditional laboratory column studies of infiltration and redistribution have not produced unstable flow, because the cylindrical cross-sectional dimensions may have been too small to display a complete wavelength of the fingers. The finger diameter $d$ has been calculated as a function of various soil properties. Parlange and Hill [1976] and Glass et al. [1989a] related it to the soil's sorptivity $S$ and the system flux ratio $F$ by

$$
d=\frac{2.4 S^{2}}{K_{s}\left(\theta_{s}-\theta_{i}\right)}\left(\frac{1}{1-F}\right)
$$

whereas Wang et al. [1998c] expressed it as a function of the water entry value $h_{w e}$ and $F$ :

$$
d=4.8 \sqrt{\varepsilon R^{*}\left|h_{w e}\right|}\left(\frac{1}{1-F}\right)^{1 / 2}
$$

where $R^{*}$ is the effective mean radius of curvature of the airwater interface at the wetting front. Based on an analysis of the 24 existing laboratory and field studies of unstable flow, reported by Wang et al. [1998c], we obtained that $0.3<R^{*}$ $<0.7 \mathrm{~cm}$, with a minimum estimation error at $R^{*}=0.5 \mathrm{~cm}$. Since the water entry matric potential is much lower (more negative) in finer textured soils, equation 3 predicts that the finger diameter will increase as texture becomes finer. This will also have a stabilizing effect on flow, since wide fingers will require more water to penetrate a given distance than narrow ones.

[8] If preferential flow in nonstructured soils is caused by fluid instability rather than simply being a consequence of variations in local soil properties, the implications for water flow and chemical transport research and management are profound. Simply by virtue of their widespread use in research and management, water flow models have gained an acceptance for simulation of flow under field conditions that arguably is not warranted by their record of achievement. They either ignore the possibility of preferential flow entirely by using the volume-averaged Richards equation to model water and solute movement, or introduce parameterintensive methods of introducing preferential flow entirely as a result of soil property variations. If preferential flow can be initiated and enforced by fluid instability during unsaturated infiltration and during redistribution following saturated infiltration in the field, these models will not predict preferential flow with their current approach.

[9] Despite the wide variation in soil conditions and experimental design, field studies of preferential flow in coarse-textured, nonstructured soils nearly all share one common feature: the time of sampling was always scheduled after a reasonable amount of redistribution occurred 
following cessation of water application. According to theory, this condition is highly conducive to propagation of a fluid instability, should any perturbation occur in a sharp wetting front. For example, the field experiment of Glass et al. [1988] reported fingering due to repeated infiltration cycles and increasing coarseness of soil with depth. This result may have been influenced by redistribution, since some period of time elapsed prior to excavation. Thus, field evidence supports the existence of preferential flow under conditions where instabilities are predicted to occur, but to date, the cause of the preferential flow has not been established.

[10] Field observation of preferential flow presents formidable difficulties to delineate the plume dynamics. Soil cores or dye tracers along trench faces reveal the final spatial location of a chemical tracer, but not the path it traveled or when it arrived. Solution sampling has a restricted zone of monitoring and frequently misses preferential flow entirely. Tile drains provide only a diluted picture of early arrival with no information about the path traveled or point of origin. Preferential flow events determined by these inexact methods are often explained speculatively using indirect sources of information (e.g., soil structural features or externally measured breakthrough curves). Quantitative understanding of the mechanisms of preferential flow will require direct observation at small spatial scales while the plume is in motion to represent the process faithfully.

[11] The objectives of this study were: to conduct field experiments to detect unstable preferential flow in nonstructured soils during infiltration and redistribution; to identify important features of preferential flow as a function of various soil conditions; and to explore whether the experimental results are consistent with existing hypotheses about fluid instability in porous media.

\section{Methods and Materials}

\subsection{Site}

[12] Preliminary screening experiments were conducted in early 1999 at 10 candidate sites in California in order to select a number of nonstructured field soils where preferential flow might occur. At each potential site, soil samples from an auger hole driven to depths of 1-3 m were brought to the surface for visual examination of soil uniformity. Ponded infiltration tests were then conducted to determine the steady state infiltration rate or the saturated hydraulic conductivity, a key parameter in the analysis of unstable flow. From the initial 10 sites, we selected three that represented a range of soil types within the nonstructured category for detailed experimentation. They are Superstition sand at the University of California Coachella Valley Research Station in Thermal, California; Delhi sand at a private field (Francisco Leal family) near the Kings River in Parlier, California; and Hanford sandy loam at the University of California Kearney Research Center in Parlier, California. The saturated conductivity of the selected soils at different depths was measured using undisturbed soil cores and a constant-head permeameter.

\subsection{Soil Descriptions}

[13] Table 1 lists the basic soil properties of the selected field soils, and Figure 1 illustrates their measured particle size distribution. These three soils had not been planted for at least three years prior to the experiment. The soil profiles were devoid of cracks, crevices, and showed no detectable signs of layering or textural variation.

[14] The Superstition sand site is located inside the UC Coachella Valley Research Station between the eastern slope of the Santa Rosa Mountains and the northwestern corner of the Salton Sea in the southern end of California. The soils in the Coachella Valley area were formed during recession of a large body of water that was drained gradually to the Gulf of California by the deep-cutting Colorado River. The surface 15 to $40 \mathrm{~cm}$ of soil is a light brownish-gray, loose-structured sand containing large quantities of both coarse and fine sand. Below $40 \mathrm{~cm}$ the subsoil consists of gray, porous, somewhat coarser sand containing a small amount of fine gravel 2 to $40 \mathrm{~mm}$ in diameter, and sporadic granite stones 100 to $400 \mathrm{~mm}$ in diameter. The soil material is almost entirely devoid of organic matter since there is almost no vegetation on the ground. It absorbs moisture readily but has a low water retention capacity. Our experiment was conducted on uncultivated soil that had never been irrigated. The temperature in the region is extremely high for most of the year with daily highs ranging between 40 and $50^{\circ} \mathrm{C}$, and lows between -4 and $16^{\circ} \mathrm{C}$.

[15] The Delhi sand in Parlier, California, is a wind-laid deposit of uniformly sorted sandy material located in a regional depression. It consists of a $15-$ to $20-\mathrm{cm}$ thick surface layer of pale-brown, slightly acid loamy sand and a $150 \mathrm{~cm}$ sub-layer of uniformly sorted sand composed of medium and fine sand particles of feldspar and quartz. The field soil used in the experiment is low in organic matter and has a history of grape growing, but has been fallow for the past 3 years. All but one of the soil plots in the study were tilled before the experiments commenced.

[16] The Hanford sandy loam in Parlier, California, is located inside the UC Kearney Agricultural Research Center. The texture of the $20-\mathrm{cm}$ surface layer is light brownishgray fine sandy loam, and the underlying material is uniformly brown sandy loam to a depth of $1.5 \mathrm{~m}$. The field was previously planted with nectarine trees with a 6-m row and tree spacing. But, those trees were removed three years ago and the soil has not been replanted. However, the soil received annual tillage for weed control. The first four experiments were conducted on top of soil tilled one year previously, while last three were conducted on freshly tilled soil with or without the surface $20-\mathrm{cm}$ layer. The Hanford sandy loam was formed from wind-laid deposits of uniformly sorted materials blown from the young alluvial fan of the Kings River. The weather of Parlier, California, in the summer months is hot (highs between 37 and $45^{\circ} \mathrm{C}$, lows between $1^{\circ}$ and $6^{\circ} \mathrm{C}$ ). The average evaporation rate is about 12 to $16 \mathrm{~mm} /$ day.

\subsection{Experimental Procedures}

[17] A total of 17 experiments (15 diagnostic and two detailed) were conducted at the three field sites under different conditions, as summarized in Table 2. The diagnostic experiments were done on four plots in the Superstition sand, five plots in the Delhi sand and six plots in the Hanford loamy sand. The purpose of these studies was to identify the basic soil and flow conditions for the onset of unstable flow during redistribution. Each plot was first irrigated, followed by redistribution for at least 5 hours, 
Table 1. Basic Properties of the Field Soils

\begin{tabular}{|c|c|c|c|c|c|c|c|c|c|c|}
\hline $\begin{array}{l}\text { Depth, } \\
\text { cm }\end{array}$ & $\begin{array}{l}\text { Bulk Density, } \\
\mathrm{g} \mathrm{cm}^{-3}\end{array}$ & $\begin{array}{l}\text { Clay, } \\
\%\end{array}$ & $\begin{array}{l}\text { Loam, } \\
\%\end{array}$ & $\begin{array}{l}\text { Sand, } \\
\%\end{array}$ & $\begin{array}{c}\text { Gravel, } \\
\%\end{array}$ & $\begin{array}{c}\text { Organic Matter, } \\
\%\end{array}$ & $\begin{array}{c}\text { Moisture Content, } \\
\text { vol. \% }\end{array}$ & $\mathrm{pH}$ & $\begin{array}{l}\mathrm{K}_{\mathrm{s}} \text { Conductivity, } \\
\mathrm{cm} \mathrm{h}^{-1}\end{array}$ & $\begin{array}{c}\text { Water Entry Pressure, } \\
\mathrm{cm}\end{array}$ \\
\hline \multicolumn{11}{|c|}{ Superstition Sand, University of California Coachella Valley Research Station, Thermal, California } \\
\hline $0-40$ & 1.67 & 2.7 & 1.8 & 80.2 & 15.3 & 0.6 & 0 & 7.47 & 25 & -10 \\
\hline $40-60$ & 1.66 & 2.2 & 1.4 & 83.7 & 12.7 & 0.5 & 1.5 & 7.78 & 33 & -7 \\
\hline $60-120$ & 1.64 & 1.8 & 2.2 & 86.2 & 9.8 & 0.5 & 2.2 & 7.78 & 33 & -5 \\
\hline Average & 1.66 & 2.23 & 1.80 & 83.36 & 12.60 & 0.54 & 1.23 & 7.68 & 30.33 & -7.33 \\
\hline $\mathrm{Cv}(\%)$ & 0.92 & 20.19 & 20.90 & 3.59 & 21.84 & 13.81 & 91.13 & 2.33 & 15.23 & -34.32 \\
\hline \multicolumn{11}{|c|}{ Delhi Sand, Francisco Leal Family Field, Parlier, California } \\
\hline $0-20$ & 1.45 & 5.0 & 2.0 & 93.0 & & 1.5 & 0 & 6.8 & 4.5 & -25.0 \\
\hline $20-30$ & 1.48 & 4.8 & 1.1 & 94.1 & & 0.8 & 3.2 & 5.7 & 6.2 & -13.0 \\
\hline $30-40$ & 1.54 & 4.9 & 1.4 & 93.8 & & 0.7 & 4.7 & 6 & 7.9 & -13.3 \\
\hline $40-50$ & 1.51 & 4.6 & 0.2 & 95.2 & & 0.7 & 5.6 & 5.9 & 8.1 & -13.2 \\
\hline $50-60$ & 1.53 & 4.8 & 3.5 & 91.7 & & 0.5 & 6.9 & 6.8 & 6.4 & -12.2 \\
\hline $60-70$ & 1.53 & 2.3 & 0.2 & 97.5 & & 0.5 & 6.8 & 6.8 & 5.2 & -12.6 \\
\hline $70-80$ & 1.53 & 3.6 & 0.8 & 95.6 & & 0.5 & 6.4 & 6.8 & 5.9 & -13.9 \\
\hline $80-90$ & 1.58 & 2.4 & 4.1 & 93.6 & & 0.5 & 6.5 & 6.8 & 7.9 & -15.4 \\
\hline $90-100$ & 1.57 & 2.4 & 5.0 & 92.6 & & 0.6 & 6.8 & 6.8 & 8.2 & -14.5 \\
\hline $100-110$ & 1.50 & 2.7 & 3.1 & 94.2 & & 0.6 & 8.4 & 6.8 & 13.0 & -13.4 \\
\hline $110-120$ & 1.48 & 4.5 & 0.8 & 94.7 & & 0.6 & 7.7 & 6.8 & 15.0 & -15.7 \\
\hline Average & 1.52 & 3.81 & 2.01 & 94.18 & & 0.69 & 5.73 & 6.55 & 8.01 & -14.7 \\
\hline $\mathrm{Cv}(\%)$ & 2.61 & 30.35 & 82.65 & 1.68 & & 40.82 & 41.16 & 6.74 & 40.37 & -24.3 \\
\hline \multicolumn{11}{|c|}{ Hanford Sandy Loam, UC Kearney Research Center, Parlier, California } \\
\hline $0-20$ & 1.45 & 11.0 & 4.0 & 85.0 & & 0.6 & 0 & $7.5^{\circ}$ & 2 & -35.0 \\
\hline $20-30$ & 1.49 & 9.0 & 3.1 & 87.9 & & 0.6 & 6.0 & 6.4 & 2.1 & -24.1 \\
\hline $30-40$ & 1.63 & 8.2 & 6.9 & 84.9 & & 0.5 & 6.0 & 6.4 & 2.1 & -14.3 \\
\hline $40-50$ & 1.62 & 8.5 & 7.1 & 84.4 & & 0.5 & 6.4 & 6.5 & 0.9 & -19.1 \\
\hline $50-60$ & 1.58 & 8.5 & 4.9 & 86.5 & & 0.6 & 6.2 & 6.5 & 2.1 & -12.5 \\
\hline $60-70$ & 1.54 & 5.2 & 3.6 & 91.1 & & 0.6 & 6.1 & 6.6 & 5.2 & -7.5 \\
\hline $70-80$ & 1.54 & 9.7 & 2.2 & 88.0 & & 0.5 & 6.2 & 6.6 & 2.9 & -14.7 \\
\hline $80-90$ & 1.55 & 7.5 & 2.6 & 89.9 & & 0.5 & 6.5 & 6.6 & 2.8 & -11.3 \\
\hline $90-100$ & 1.55 & 7.8 & 4.7 & 87.5 & & 0.6 & 6.9 & 6.7 & 2.9 & -19.0 \\
\hline $100-110$ & 1.58 & 5.3 & 4.7 & 90.0 & & 0.5 & 7.0 & 6.7 & 2.6 & -14.6 \\
\hline $110-120$ & 1.56 & 5.1 & 2.1 & 92.8 & & 0.6 & 7.1 & 6.8 & 2.7 & -16.2 \\
\hline Average & 1.55 & 7.81 & 4.18 & 88.02 & & 0.56 & 5.85 & 6.66 & 2.57 & -17.11 \\
\hline $\mathrm{Cv}(\%)$ & 3.30 & 24.60 & 40.83 & 3.12 & & 6.25 & 33.85 & 4.57 & 41.29 & -43.14 \\
\hline
\end{tabular}

${ }^{a}$ Estimated from the soil water retention curves [Wang et al., 1998a].

and then a trench face was extended laterally into the plot to expose the wetted profile during the following 2-3 days and allow it to be photographed. Based on the preliminary tests, the final two experiments were designed and conducted on the Delhi sand and the Hanford loamy sand to allow both photographic records and intensive soil coring to characterize the redistributing water profiles at various times.

\subsection{Fluid Application Apparatus}

[18] The experimental setup consisted of a series of $2 \mathrm{~m} \times$ $1.2 \mathrm{~m}$ plots, each of which was irrigated continuously using a moving spraying system originally designed by Ghodrati et al. [1990]. A few crucial improvements were made after our first experiment to avoid refilling the water container during application, prevent clogging of the nozzles and improve the application uniformity. The small water container (10 gallons) on top of the moving cart and the air-compressing system were removed and replaced with a 100-gallon water tank, a submersible pump (Model 4RK86, Little Giant Pump Company, Oklahoma City) and a fine-meshed filter installed at the exit of the pump. Although the nozzles contained internal filters, it was more important to filter the water before it reached the spray bar, because sedimentation in any of the nozzles would cause serious nonuniform supply along the 1.4-m long spray bar. To further improve the uniformity, we reduced the spacing of the 6 nozzles from the original $25-\mathrm{cm}$ to $20-\mathrm{cm}$. The height of the nozzles was also raised from 20 $\mathrm{cm}$ to $40 \mathrm{~cm}$ above the soil surface. Additionally, the manual switching system for the motor-driven, bidirectional cart was also automated by installing an electronic relay system so that

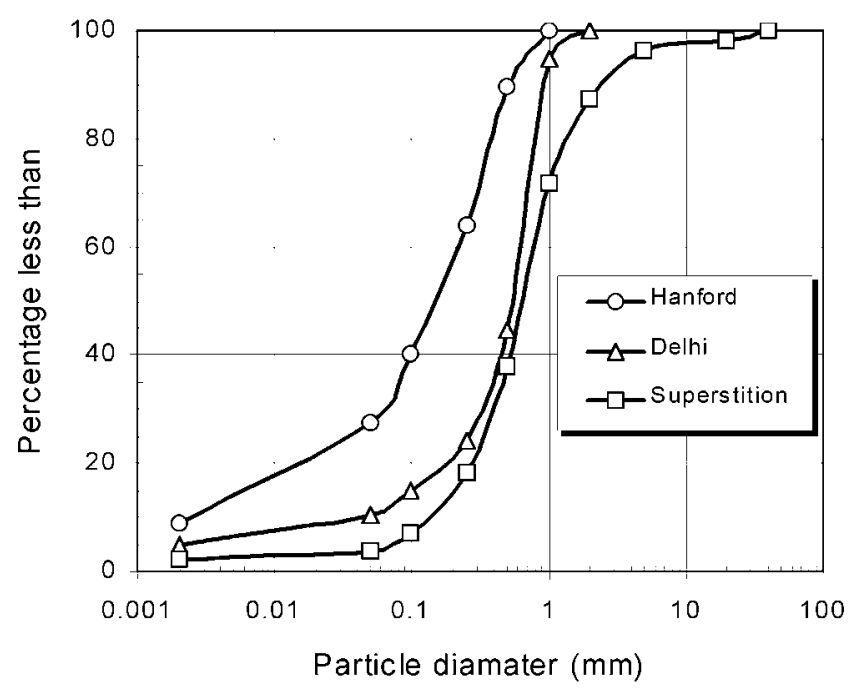

Figure 1. Particle distribution of the field soils. 


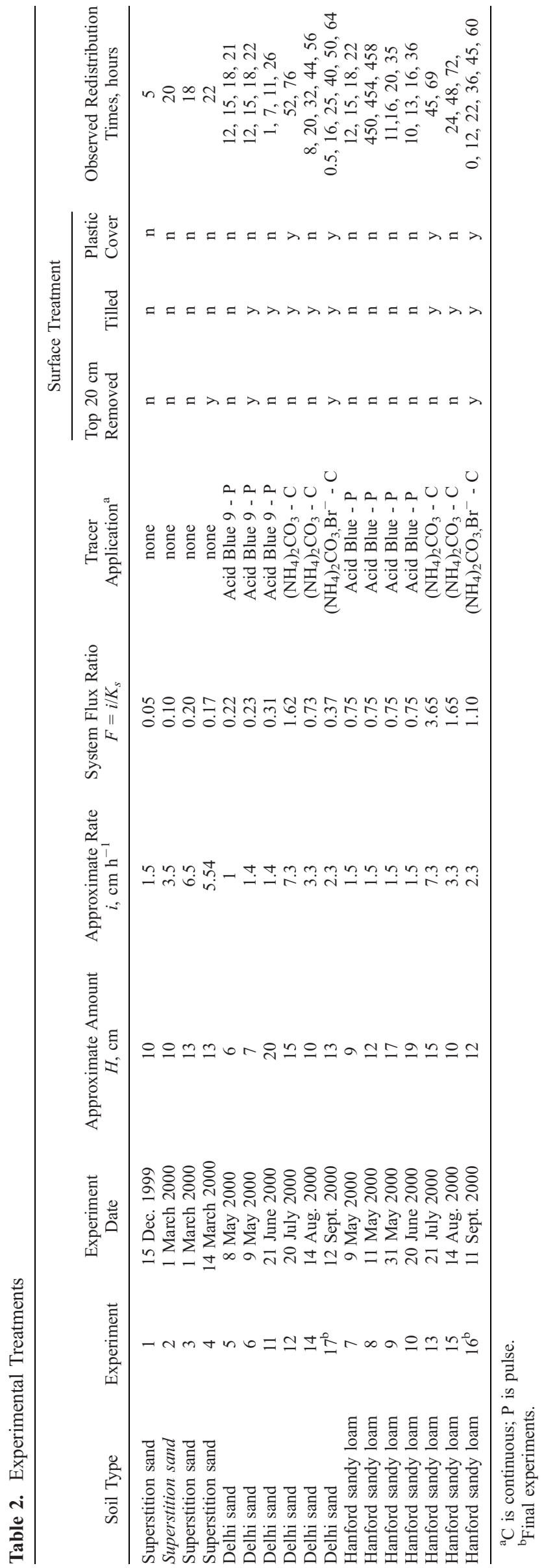

when the spraying cart hit a switch at both ends of the supporting frame $(1.5 \mathrm{~m}$ wide, $2 \mathrm{~m}$ long and $50 \mathrm{~cm}$ high) it could reverse direction automatically. To avoid wind effects and prevent excess evaporation, the spray cart and the supporting frame were curtained with plastic sheets in the field. The improved application apparatus produced a sustainable, uniform wetting band about $10 \mathrm{~cm}$ wide and $140 \mathrm{~cm}$ long on the ground. It took the moving cart $30 \mathrm{~s}$ to completely cover the plot once. The rate of application was adjusted by choosing different sized nozzles (TeeJet series), whereas the amount of water application was controlled by precisely filling the water tank to a desired level (see Table 2).

\subsection{Dye and Tracer Application}

[19] It was not necessary to use tracers on the Superstition sand, because the soil profile was initially dry to a large depth and the wetting front was clearly visible. However, the wetting front was not detectable in the Delhi sand and the Hanford sandy loam, where soil moisture increased with depth (Table 1). Thus, for the first few preliminary experiments on these latter two sites (Table 2), a water-soluble, anionic brilliant blue dye (Acid Blue 9 from Keystone Aniline Corp., Chicago, Illinois 60612) was applied either as an initial high-concentration pulse $(2-5 \%)$ or as continuous lower-concentration solution (1\%) for visualizing the wetting front. Since there were signs of dye retardation in the Delhi and Hanford soils, we developed a $\mathrm{pH}$ indicator method to detect the flow patterns in the dye-retarding soils [Wang et al., 2002]. A $2.5 \%$ water solution of ammonium carbonate was applied, which elevated the soil $\mathrm{pH}$ value to about $8.2-8.5$. A $\mathrm{pH}$ indicator was prepared using a $1 \%$ weight of thymol blue (ACS Reagent, Dye content 95\%) and another 1\% weight of cresol red (Indicator grade, dye content $\sim 95 \%$ ) which were dissolved into methanol at $95 \%$ purity. Five to ten minutes after spraying a mist of this $\mathrm{pH}$-indicator onto the soil profile, the ammonium carbonate-affected areas would become purple-red, while the unaffected areas become yellow. The yellow/red contrast was highly visible for photographic recording. The infiltration solution also contained $0.5 \%$ weight of potassium bromide, so that the $\mathrm{Br}^{-}$concentration could be used to check the position of wetting front and the water distribution inside the wetted areas.

\subsection{Excavation, Photography and Sampling}

[20] Prior to irrigation, we dug a small trench adjacent to the plot using a backhoe, and both bulk soil samples and soil cores $(5.4 \mathrm{~cm}$ i.d., $6 \mathrm{~cm}$ long) were taken for measuring the background soil physical and chemical properties. In the preliminary experiments, we dug into the wetted plot area at times ranging from 5 to 458 hours (Table 2) after application of the tracer fluid. A vertical soil profile, $1 \mathrm{~m}$ deep and $1.2 \mathrm{~m}$ wide, was prepared by cutting and shaving smoothly using a flat shovel, after which the trench face was sprayed with the $\mathrm{pH}$ indicator. When a colored flow pattern emerged after 5 to $10 \mathrm{~min}$, a $1.2-\mathrm{m}$ by $1-\mathrm{m}$ metal frame, made of $10 \times$ $10 \mathrm{~cm}$ steel bar grids, was placed onto the soil profile, and the flow pattern was photographed using a $35-\mathrm{mm}$ digital camera. A total of 3-6 trench faces were dug along the 2-m long plot at equal distances every 3 to 12 hours depending on the soil texture and experimental design.

[21] For the final two intensive experiments conducted on the Delhi sand and Hanford sandy loam, six trench faces were dug along the first half (1-m long) of the plot at a 20 - 


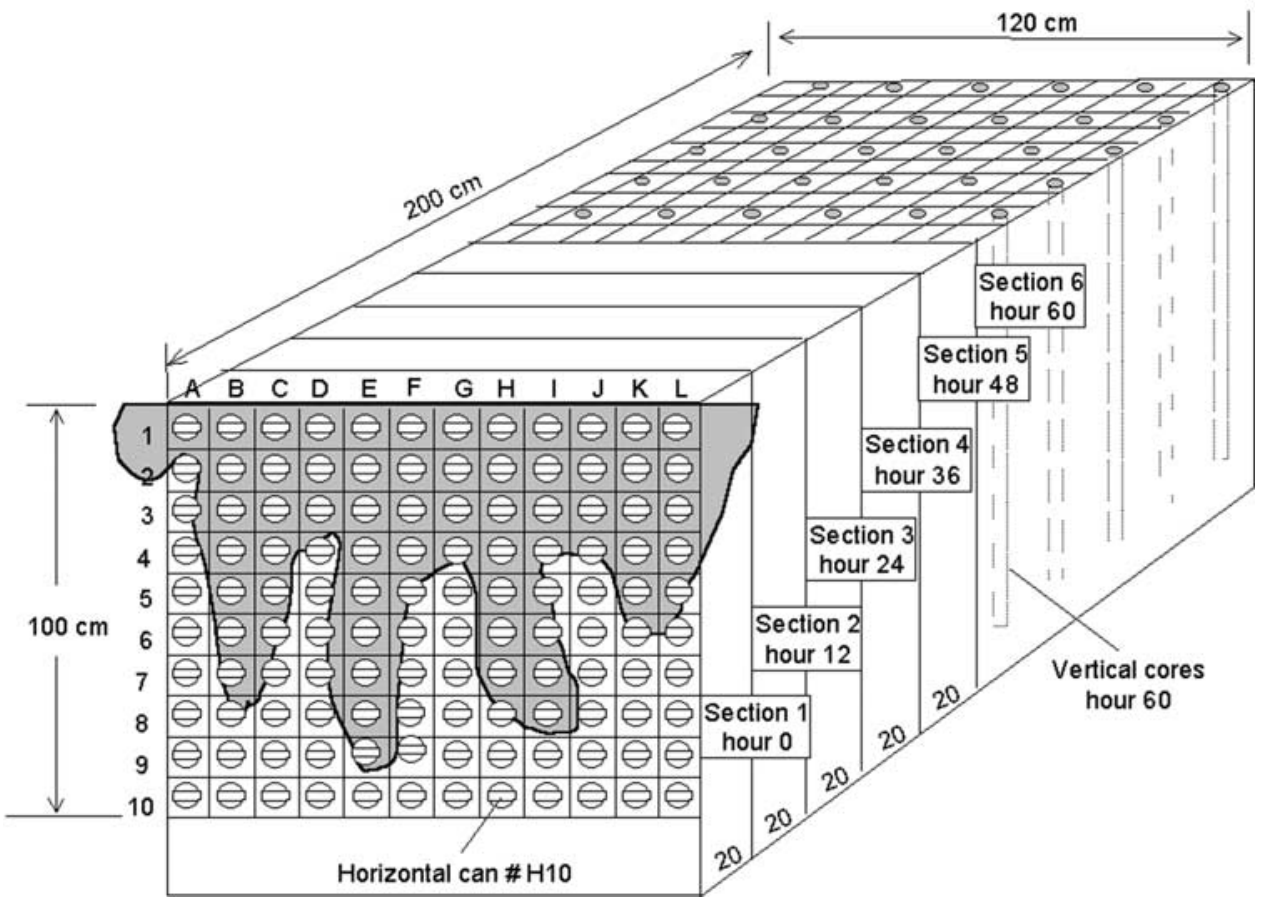

Figure 2. Scheme of intensive sampling in the field plot.

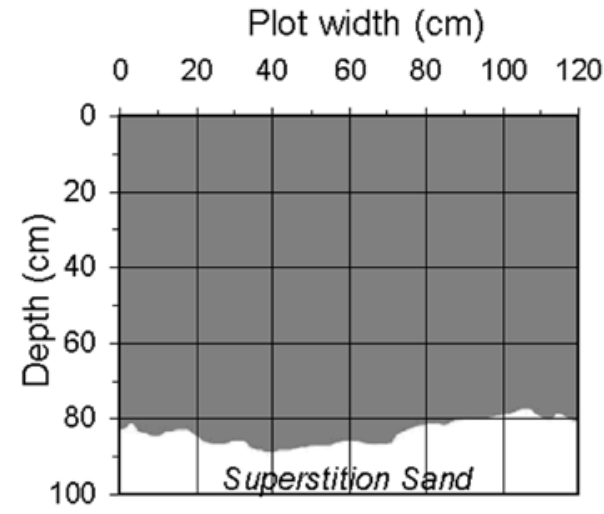

(a) Exp. 4: $\mathrm{F}=0.17, \mathrm{H}=13 \mathrm{~cm}, \mathrm{t}=22 \mathrm{~h}$

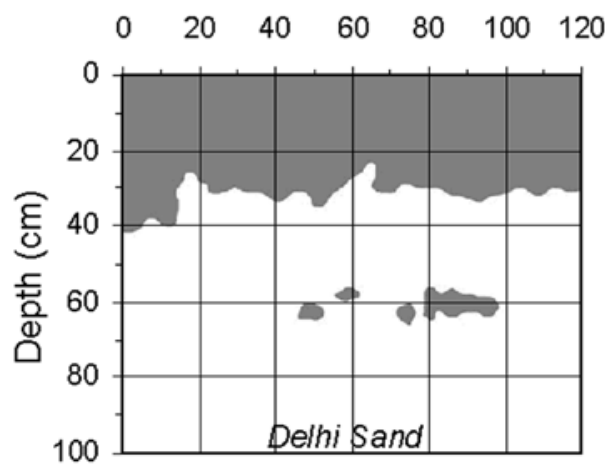

(c) Exp. 17: $\mathrm{F}=0.37, \mathrm{H}=13 \mathrm{~cm}, \mathrm{t}=16 \mathrm{~h}$
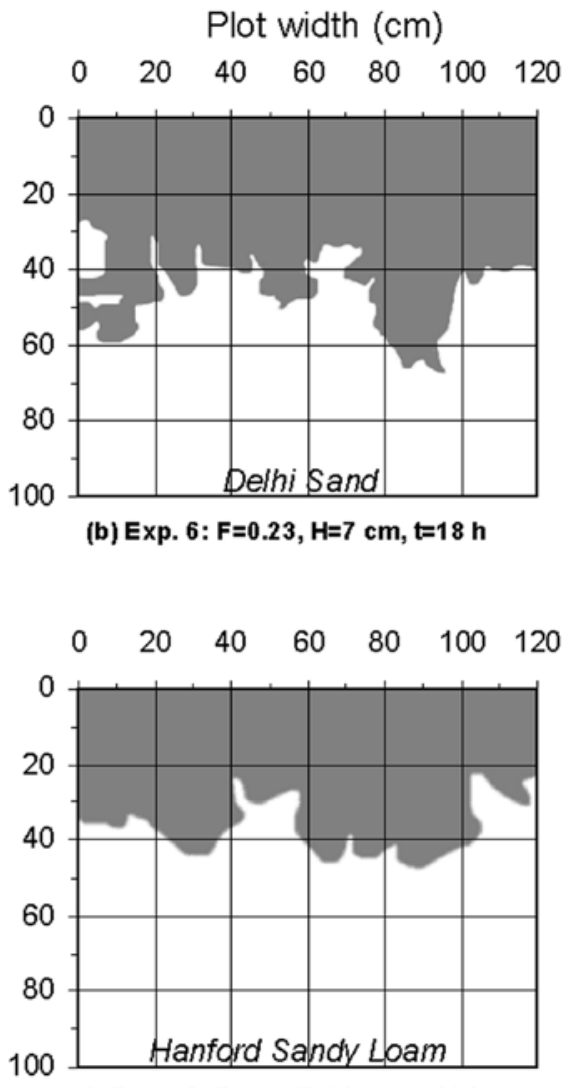

(d) Exp. 16: F=1.1, $\mathrm{H}=12 \mathrm{~cm}, \mathrm{t}=22 \mathrm{~h}$

Figure 3. Vertical flow patterns developed during soil water redistribution in homogeneous soil profiles (without the surface fine layer). $F$ is the ratio of application rate to saturated hydraulic conductivity of the soil, $H$ is the application amount, and $t$ the time since the end of infiltration. 


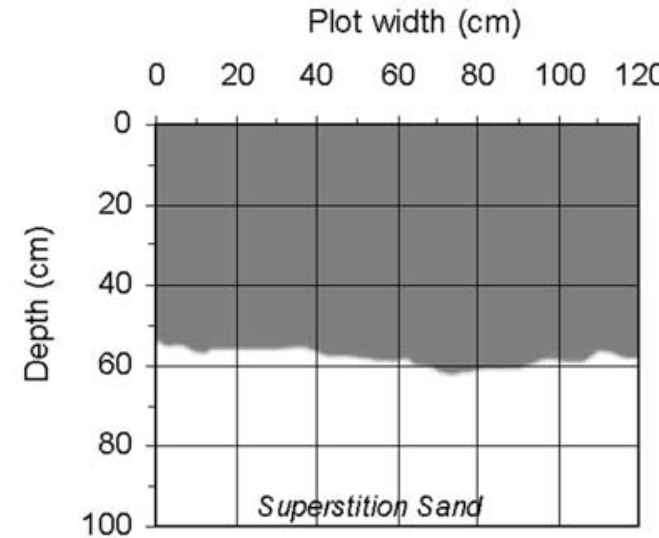

(a) Exp. 1: $\mathrm{F}=0.05, \mathrm{H}=10 \mathrm{~cm}, \mathrm{t}=5 \mathrm{~h}$

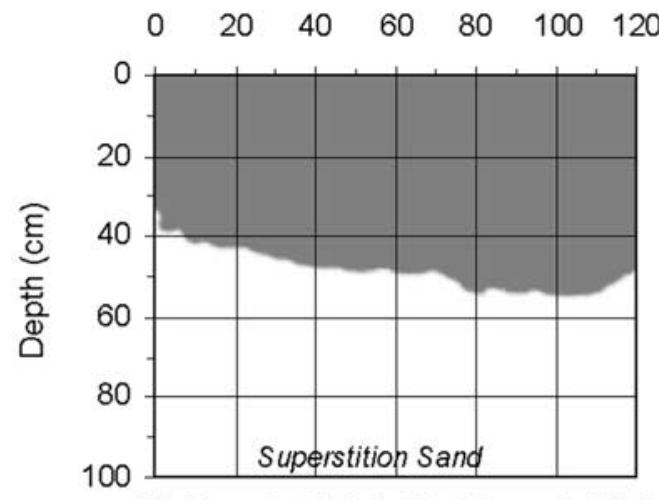

(b) Exp. 2: $\mathrm{F}=0.1, \mathrm{H}=10 \mathrm{~cm}, \mathrm{t}=20 \mathrm{~h}$

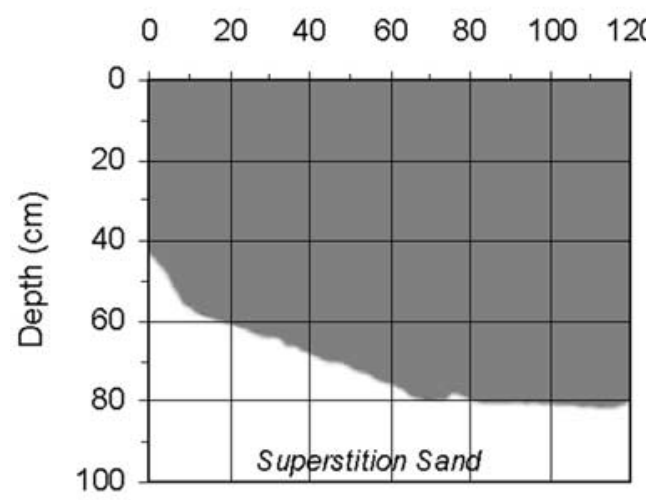

(c) Exp. 3: $\mathrm{F}=0.2, \mathrm{H}=13 \mathrm{~cm}, \mathrm{t}=18 \mathrm{~h}$

Figure 4. Stable flow patterns in Superstition sand.

$\mathrm{cm}$ spacing at about 12-hour time intervals starting immediately at the end of infiltration (Figure 2). The soil surface and trench faces were covered by a plastic membrane during times between excavations to prevent excessive evaporation of applied water and ammonia. Bulk samples were also taken and analyzed for bromide and water content by horizontally pushing and removing soil cans $(5.4 \mathrm{~cm}$ i.d., $6 \mathrm{~cm}$ long) at the center of every 10 by $10 \mathrm{~cm}$ grid. Immediately after the final trench face (section 6) was excavated and sampled, vertical core samples were taken in the second half (1-m long) of the plot using a multiple core sampler (Arts Manufacturing \& Supply Inc., American
Falls, Idaho) to provide a detailed characterization of the final profile. The sampler consisted of a hollow-stem auger (5.4 cm i.d., $35 \mathrm{~cm}$ long), 3 sampling tubes $(5.1 \mathrm{~cm}$ i.d., 7.6 $\mathrm{cm}$ long) with aluminum liners, a threaded auger cap and a compact slide hammer. To avoid cross contamination during the sampling, the aluminum liners were rinsed with methanol prior to reuse. The sampler was pushed down to a maximum depth of $100 \mathrm{~cm}$ in the center of every 20 by 20 $\mathrm{cm}$ grid on the soil surface (Figure 2). The recovered intact cores were separated into ten sub-samples, and were immediately sealed into zip-lock plastic bags and stored in chest coolers on the site. Upon returning to the laboratory, all the samples were stored in the $4^{\circ} \mathrm{C}$ cold room.

\subsection{Measurement of Soil Water Potential}

[22] Four tensiometers (two each at 10 and $50 \mathrm{~cm}$ below the surface) were installed at the centers of the first and second half of the plots used in the final two experiments. Readings were taken every 30 min during infiltration and at the times of excavation during redistribution.

\subsection{Laboratory Measurements}

[23] Bulk density, moisture content, hydraulic conductivity, moisture release curves, and particle size distribution were measured on samples taken from each soil type by the standard methods described by Klute [1986]. Soil organic matter content was measured using the combustion method. The bromide concentrations were measured using the automated Phenol Red Method with an Alpkem RFA-300 Rapid Flow Analyzer manufactured by Astoria-Pacific International, Clakamas, Oregon.

\subsection{Analysis of Data}

[24] The photographs in the digital camera were downloaded into the computer, and the stained patterns were enhanced and orthoganalized to a rectangular grid using Photoshop image processing software. The digital flow patterns were used for shape analyses. The soil moisture and bromide concentration data from each trench face were converted into two-dimensional contour plots using Golden Software Surfer 7.0. Data from all profiles were also converted into three-dimensional views using software packages called RockWorks99 (Rockware Earth Science Software, 1999) and Slicer Dicer (Version 3, Pixotec, LLC, 1999).

\section{Results and Discussion}

\subsection{Flow Patterns in a Homogeneous Profile}

[25] Laboratory experiments of Diment and Watson [1985], Selker et al. [1992] and Yao and Hendrickx [1996] proved that unstable flow occurs during redistribution in sieved homogeneous sands. However, demonstrating that redistribution causes unstable flow in a natural field soil can be difficult, because any pronounced layering in the soil profile can also cause unstable flow if a coarser layer underlies a finer one. The soil profiles in our field sites are most homogeneous between $20 \mathrm{~cm}$ and $150 \mathrm{~cm}$ below the surface, so we removed the top $20 \mathrm{~cm}$ in a subset of our plots.

[26] Figure 3 shows the flow patterns observed for the four experiments carried out without the surface layer (Table 2) following a redistribution time $t$ of 16-22 hours. Contrary to our expectation, the redistribution flow in the coarsest 


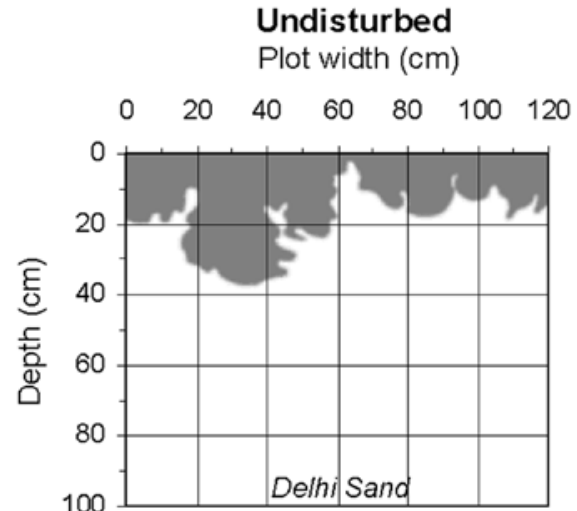

(a) Exp. 5: $\mathrm{F}=0.22, \mathrm{H}=6 \mathrm{~cm}, \mathrm{t}=21 \mathrm{~h}$

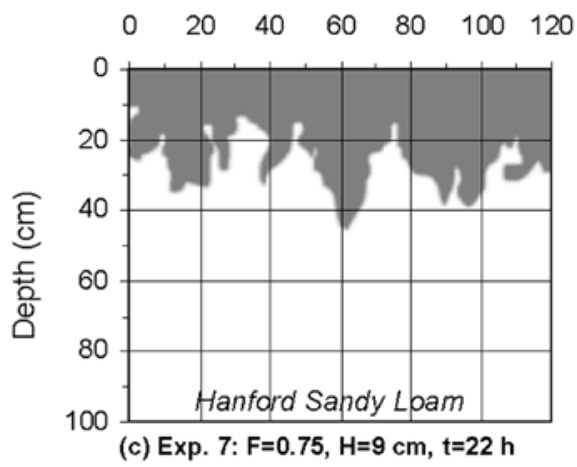

Tilled

Plot width $(\mathrm{cm})$

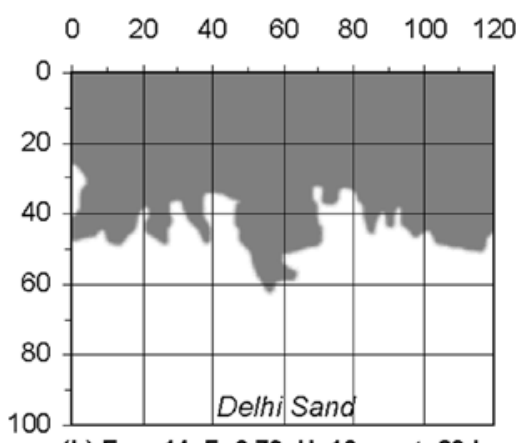

(b) Exp. 14: $\mathrm{F}=0.73, \mathrm{H}=10 \mathrm{~cm}, \mathrm{t}=20 \mathrm{~h}$

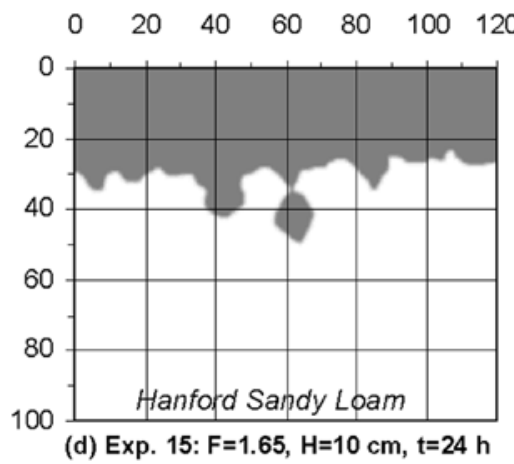

Figure 5. Effects of surface disturbance on flow patterns.

material, Superstition sand, was clearly stable (Figure 3a). However, flow patterns in the finer materials, Delhi sand and Hanford sandy loam (Figures 3b-3d), were apparently unstable, showing fingered patterns and isolated patches in regions where no crevices or root channels were observed. Since the saturated conductivity of the Superstition sand was the highest of the three soils (Table 1), the system flux ratio $F$ was the lowest among the four treatments. The rapid decline of wetting front velocity during redistribution may explain why this soil has a stable draining front. According to equation (1), the wetting front should stabilize in the Superstition sand $\left(h_{w e}=-7 \mathrm{~cm}\right)$ when the flux ratio $F$ declines below 0.006 (about $4-5 \mathrm{~cm} / \mathrm{d}$ for this soil), at which time the soil capillary forces would begin to dominate gravitational forces. With minor textural differences between the surface and sub layers, the entire Superstition sand including the 20cm surface layer consistently supported "stable" flow as shown in Figure 4 at various redistribution times. Another feature of the Superstition sand that distinguishes it from the other two soils is the high percentage of large particles and gravel. Over $30 \%$ of the soil is comprised of particles larger than $1.0 \mathrm{~mm}$, and it contained a substantial amount of gravel and stones (Figure 1). We also observed that fine particles tended to accumulate in the spaces between the large particles, which could conceivably enhance the effects of capillary forces on retarding the advance and spreading out a developing instability.

\subsection{Effects of Surface Soil Disturbance}

[27] Comparison of the effect of removing or retaining the surface layer of soil is shown in Figure 5. Under various flux ratio $(F)$ and application amounts $(H)$, fingered flow developed in both the undisturbed and tilled soils. However, fingers started at a shallower depth (or an earlier time) in the undisturbed soil than in the tilled soil. The disturbed $20-\mathrm{cm}$ layer was uniformly wetted, and fingers developed only after this zone was traversed. The shape of the wetting front in the undisturbed soils was more complicated than in the tilled, and showed evidence of fingering in the top $20 \mathrm{~cm}$. Based on our results we conclude that soil surface tillage can prevent preferential flow in the disturbed layer but not below it.

\subsection{Effects of Infiltration Amount and Redistribution Time}

[28] Our experiments encompassed various amounts of water application $(6-20 \mathrm{~cm})$ and redistribution times $(5-$ 458 hours), as shown in Table 2. While flow in the Superstition sand was always stable, fingered flow persistently occurred in the Delhi sand and Hanford sandy loam with or without tillage or plastic coverage. In a special experiment (\#8), soil water was allowed to redistribute for 458 hours in the Hanford soil after $12 \mathrm{~cm}$ of water application. The finger depth did not extend beyond $60 \mathrm{~cm}$, indicating that redistribution ceased after some period of time, even in the fingered flow paths. On the other hand, the large $20 \mathrm{~cm}$ water application to the Delhi sand in experiment 11 produced a small finger that penetrated below the 1-m observation depth.

\subsection{Dynamics of Fingering During Redistribution}

[29] Figure 6 shows the results of experiments 16 and 17 on the Hanford and Delhi soils where intensive trench facing and sampling were conducted as shown in Figure 2. The 


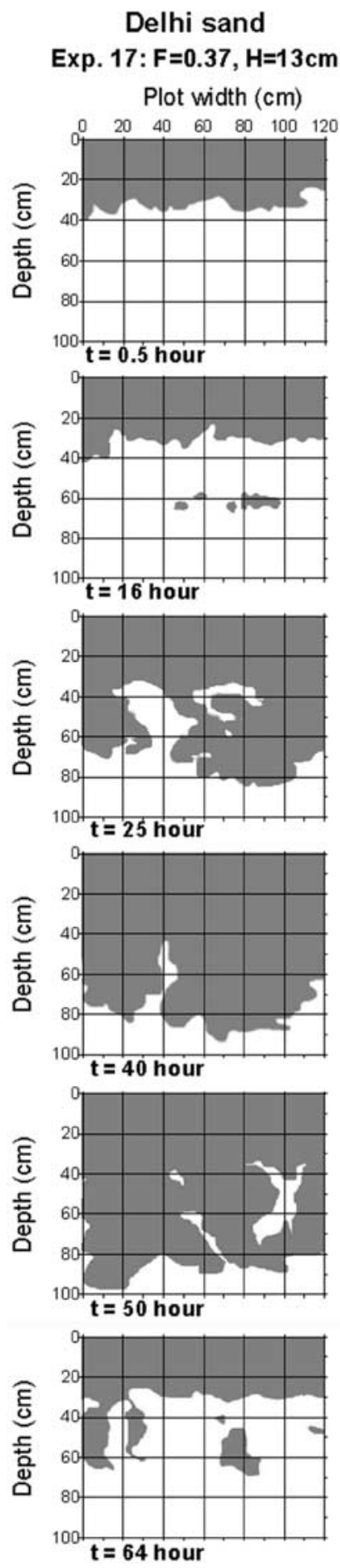

Hanford sandy loam
Exp. 16: $F=1.1, H=12 \mathrm{~cm}$ Plot width $(\mathrm{cm})$
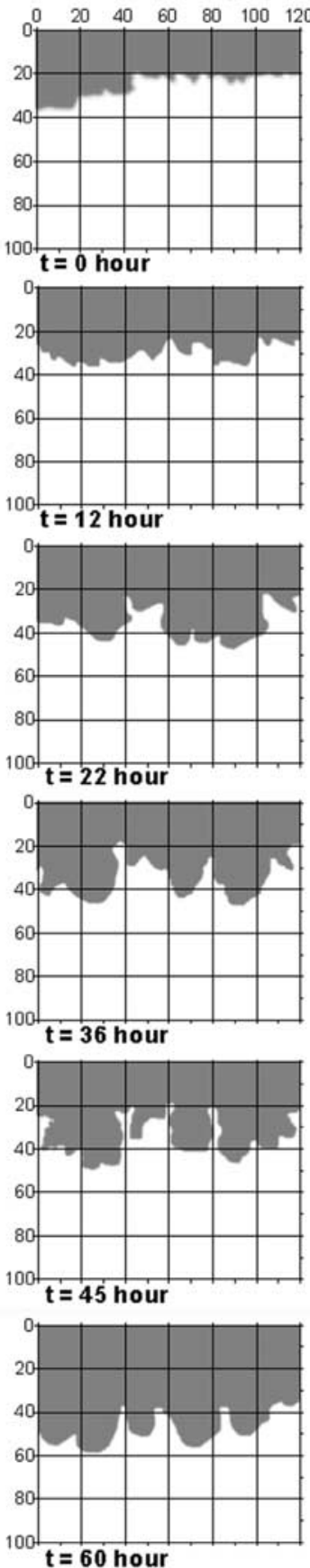

Plot Length

$0 \mathrm{~cm}$

$20 \mathrm{~cm}$

$40 \mathrm{~cm}$

$60 \mathrm{~cm}$

$80 \mathrm{~cm}$

$100 \mathrm{~cm}$

Figure 6. Variation of flow patterns with time and space during redistribution.

shapes of the unstable wetting front varied greatly with time and space, but there is a clear tendency for the wetting front to become progressively more irregular over time. Generally, the initial wetting front at the end of infiltration $(t<0.5$ hour) was nearly flat. The wetting front in the Delhi sand became finger-like after 16 hours of redistribution, whereas in the Hanford sandy loam, the finger patterns emerged after 22 hours of redistribution.

[30] Several types of analysis were used to identify fingering patterns in the dye trace records. First, a tortuosity factor $\tau$ was defined as the ratio of the length of the wetting front in cross section to the horizontal width of the plot. This factor would equal 1.0 for a uniform wetting front and increase with the degree of irregularity of the profile. Second, finger dimensions were measured for each plot, after first arbitrarily defining a finger as an isolated plume whose length was comparable to or greater than its width at the base.

[31] Figure 7 shows the measured tortuosity factor for all of the experiments reported in this study. The lines con- 


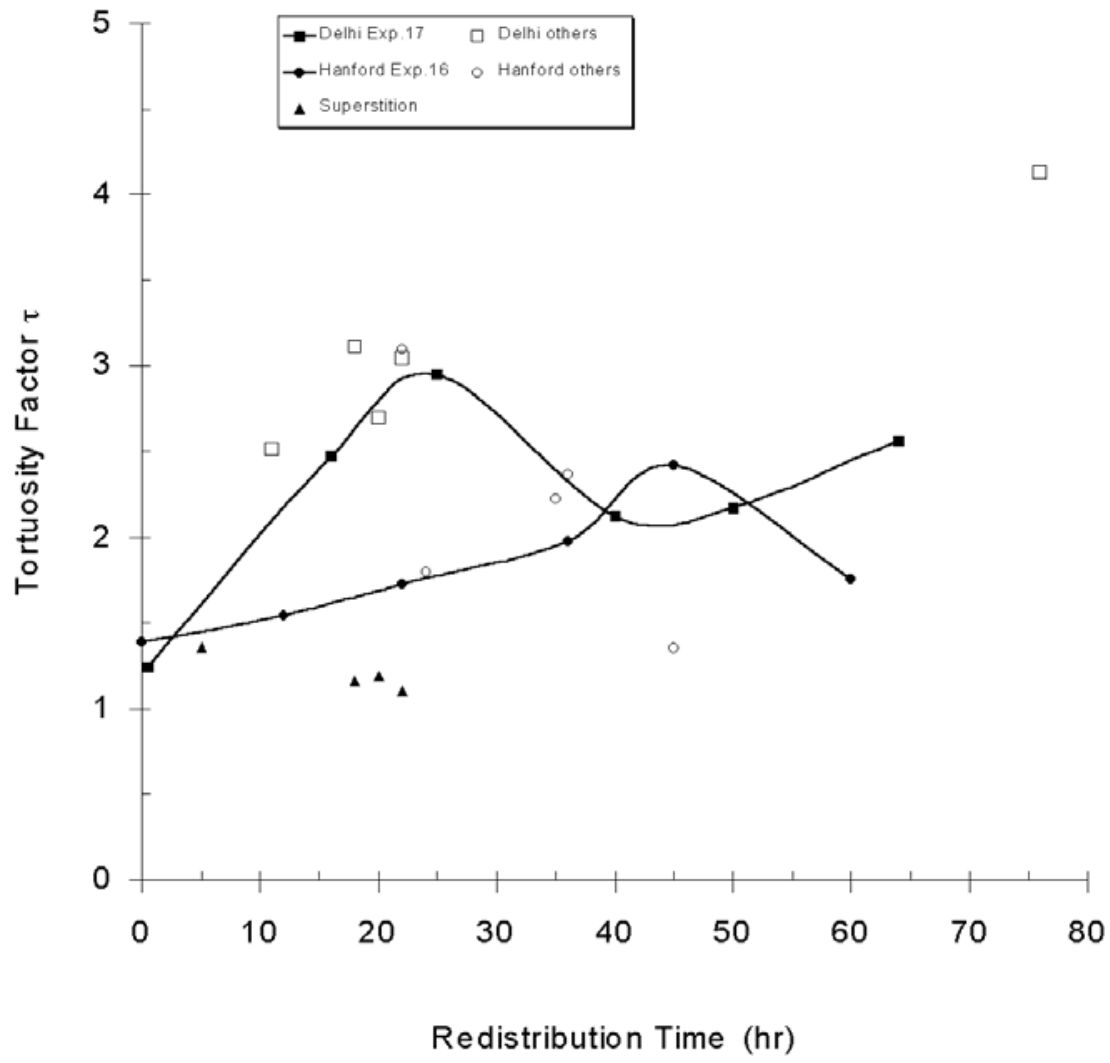

Figure 7. Tortuosity factor of the wetting front versus redistribution time for all of the experiments in the study. Lines are drawn through successive times of the multiply sampled plots in experiments 16 and 17.

necting the solid symbols are the multiply sampled plots for the Hanford and Delhi experiments. Several features are obvious from Figure 7. First, tortuosity is near 1.0 in all soils at the end of infiltration, indicating a stable wetting front. The tortuosity increases significantly during redistribution in the Delhi and Hanford soils, reaches a plateau, and then declines in the multiply sampled plots. The decline at larger times could indicate that capillary diffusion is smoothing out the front. In contrast, there is no increase in tortuosity over time in the Superstition sand, confirming that the redistribution front is stable in this soil.

[32] Table 3 summarizes the finger characteristics averaged over all experiments in each soil. There were no trends observed by comparing treatments within a soil type. Mean finger widths are comparable in the Delhi and Hanford soils (12.8 and $13.6 \mathrm{~cm}$, respectively), and are consistent with the finger diameter range estimated using equation 3 . The water entry matric potentials $\left(h_{w e}\right)$ for the various soil depths were estimated from the measured moisture release curves [Wang et al., 1998a], and the flux ratio was taken as the ratio of the infiltration rate to the saturated hydraulic conductivity. The average length of finger was considerably longer in the coarser textured Delhi sand than in the Hanford sandy loam $(22.2$ versus $13.5 \mathrm{~cm})$. The former soil drains to a lower water content than the latter, so that more water is channeled into the fingers from the surrounding matrix. Both soils have approximately half of the wetting front covered by fingers, which would be the percent coverage of a periodic sinusoidal disturbance. The number of fingers per cross section varied from 4 to 7 with an average of 5 in the Hanford soil, and from 3 to 6 with an average of 4.4 in the Delhi soil.
[33] The dynamics of redistribution observed in this study resemble the pattern of intermittent flow reported by several other investigations [Glass et al., 1989c; Nicholl et al., 1994; Glass and Nicholl, 1996; Su et al., 1999] in soils and fractured rock where the total downward flow was carried by a few saturated, intermittently advancing plumes which decreased in size as they advanced. They would stop when their volume became too small, then move again when recharged by gradual supply through fingered paths from the upper layers. Glass et al. [1989b] used light transmission to monitor finger movement during infiltration and speculated that the finger tip is composed of a nearly saturated zone with a height slightly longer than the difference between the water and air entry values. This hypothesis was later validated by Selker et al. [1992] and Geiger and Durnford [2000] using fast response minitensiometer measurements. Our field measurement for the redistribution process seemed to have produced similar results in terms of wetting front dynamics. Furthermore, the surface water in our experiment seemed to have moved through horizontal induction zones

Table 3. Finger Characteristics Measured From Dye Cross Sections and Predicted From Equation $3^{\mathrm{a}}$

\begin{tabular}{lccccc}
\hline \multicolumn{1}{c}{ Soil } & Number & $\begin{array}{c}\text { Width, } \\
\mathrm{cm}\end{array}$ & $\begin{array}{c}\text { Length, } \\
\mathrm{cm}\end{array}$ & $\begin{array}{c}\text { Percent } \\
\text { Coverage }\end{array}$ & $\begin{array}{c}\text { Predicted Width, } \\
\mathrm{cm}\end{array}$ \\
\hline Delhi & $4.4(1.0)$ & $12.8(5.8)$ & $22.2(12.2)$ & 47 & $12.5-14.0$ \\
Hanford & $5.0(1.0)$ & $13.6(5.3)$ & $13.5(6.5)$ & 56 & $9.8-17.6$ \\
\hline
\end{tabular}

${ }^{\text {a }}$ Standard deviations are given in parentheses.

${ }^{\mathrm{b}}$ Measured from the base of the finger. 


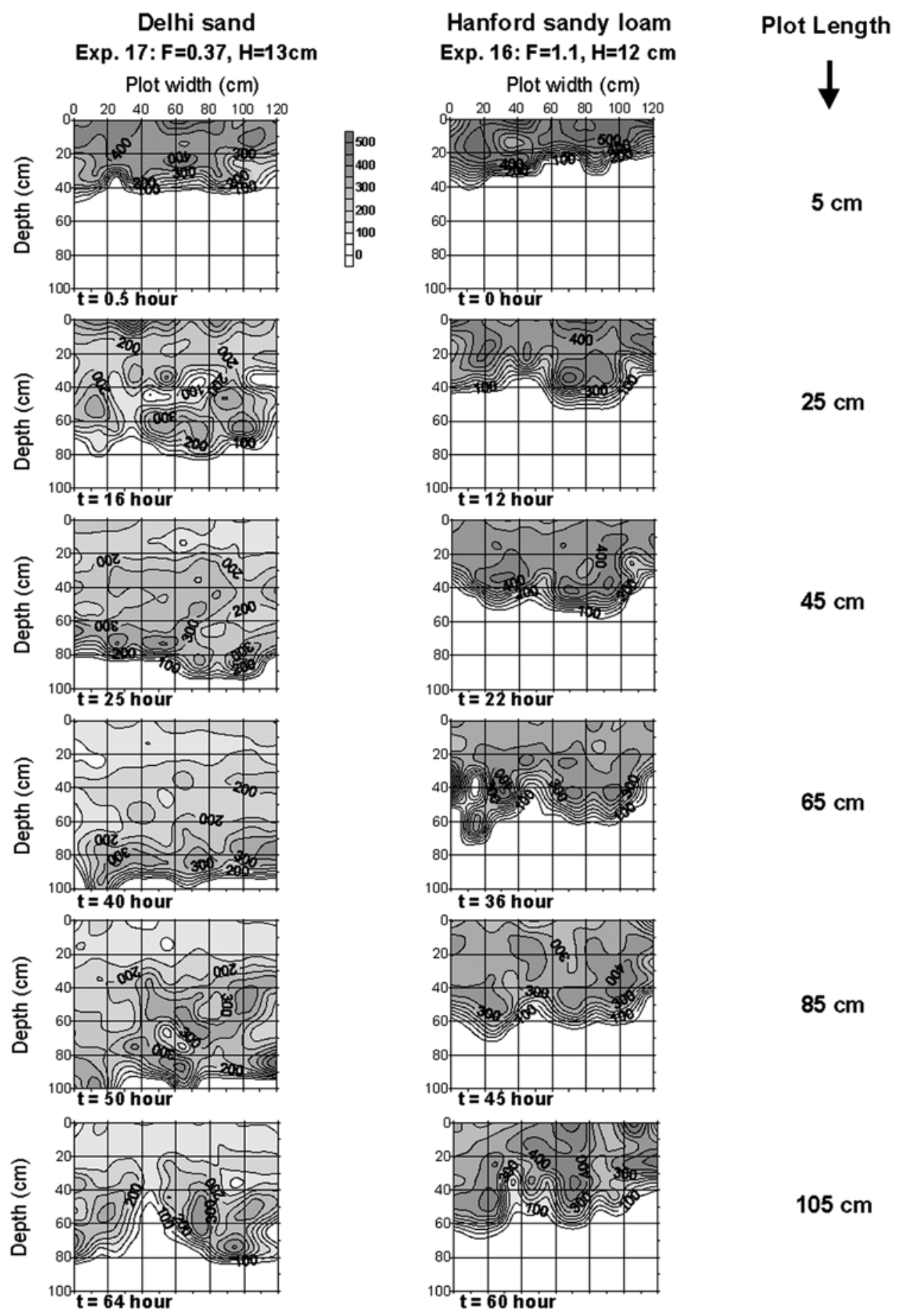

Figure 8. Redistribution of bromide concentration $(\mathrm{mg} / \mathrm{L})$ with time and space. See color version of this figure at back of this issue.

as observed by several other authors [Selker et al., 1992; Ritsema et al., 1993, 1996; Rooij and Cho, 1999; Si et al., 1999]. Similar water flow patterns have been observed on rough-walled rock fractures [Nicholl et al., 1994; Glass and Nicholl, 1996; Su et al., 1999].

[34] Figure 8 shows the two-dimensional distribution of bromide concentration inferred from horizontal samples cut 5 -cm into the trench faces used for photographic recording (Figure 6). Since the contour lines were constructed using interpolation, the true wetting front should be somewhat behind the 50-ppm line. Contour lines of $>200-\mathrm{mg} / \mathrm{L}$ indicate that the wetting pattern at the beginning of redistribution $(\mathrm{t}<0.5$ hour) was nearly uniform, indicating a stable condition. However, during extended hours of redistribution, the shape of the wetting front transformed into isolated, highly concentrated $(>300 \mathrm{mg} / \mathrm{L})$ zones. These zones of high concentration migrated away from the soil surface and congested near the wetting front, causing the frontal areas to be highly concentrated. The upper areas of the wetted region are significantly depleted of bromide, 

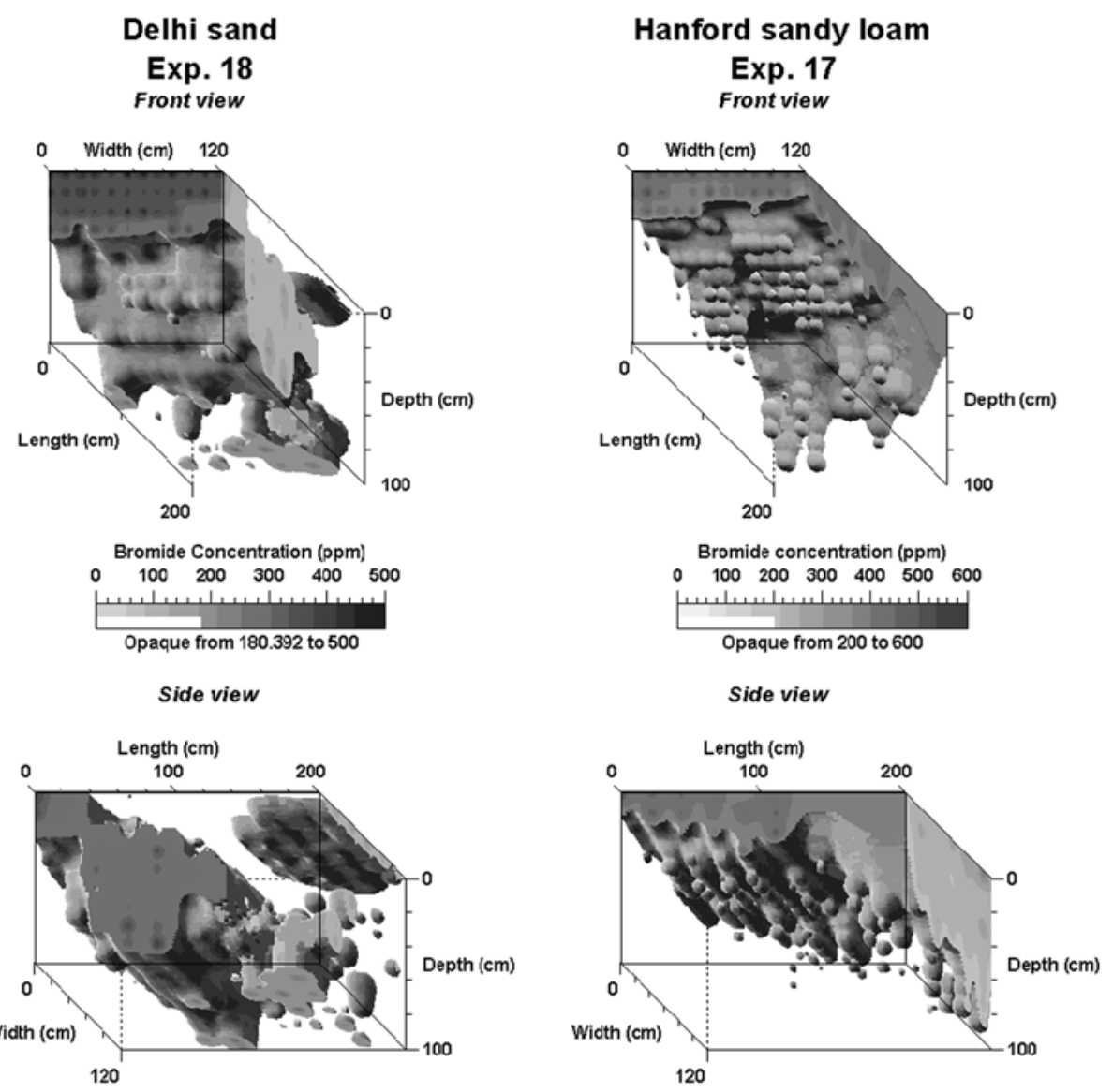

Figure 9. Three-dimensional view of highly $\mathrm{Br}^{-}$concentrated volumes in the soil.

except for sporadic islands of high concentration $(>200 \mathrm{mg} /$ $\mathrm{L})$ hanging in the central areas between the soil surface and the wetting front.

[35] Three-dimensional views of the bromide distribution are shown in Figure 9. Images in the first half of the plot (length $=0-100 \mathrm{~cm}$ ) represent the data from the trench faces (Figure 8) and images in the second half (100-200 $\mathrm{cm}$ ) reflect sampled data using vertical cores (Figure 2). In the Delhi sand, the highly concentrated mobile flow $(>200$ $\mathrm{mg} / \mathrm{L}$ ) largely percolated below the $100-\mathrm{cm}$ observation depth through a few fingers. A number of highly concentrated plumes are still hanging in the soil profile. Notice that the surface layer in the second half of the plot remained highly concentrated indicating the effects of plastic coverage during redistribution and also, possibly, the horizontal induction flow. In the Hanford sandy loam, redistribution remained within the $100-\mathrm{cm}$ observation depth, with several regions showing clear indication of wetting front instability.

[36] The measured soil water potentials in the two plots indicate that the matric potential gradient between $10 \mathrm{~cm}$ and $50 \mathrm{~cm}$ did reverse in the Delhi sand (Figure 10a) but not in the Hanford sandy loam (Figure 10b), because the flow did not reach the $50 \mathrm{~cm}$ depth in the latter field. The soil water potential at the $50-\mathrm{cm}$ depth of the Hanford plot remained below $-200 \mathrm{~cm}$ of water, reflecting the initial moisture regime. However, judging from the contour patterns of bromide redistribution in Figure 8 , it is probable that the matric potential gradients reversed in the wetted regions above $50 \mathrm{~cm}$ and induced the observed instabilities.

\section{Conclusions}

[37] Our field experiments documented the occurrence of preferential flow during soil water redistribution following the cessation of infiltration in two nonstructured field soils. Symptoms of the unstable flow observed in the Delhi sand and Hanford sandy loam field soils included irregularly shaped fingers that tended to become narrower toward their tips, isolated patches, and highly concentrated areas of the tracers in the transmission zone. The tortuosity of the wetting front was close to 1.0 at the end of infiltration, indicating stability, but increased significantly during redistribution. Soil moisture and tracer measurements revealed that the redistribution flow became fingered following a reversal of matric potential gradient within the wetted area.

[38] Contrary to our expectation, the wetting front in the Superstition sand appeared to be stable in repeated experiments despite the fact that it is much coarser in texture than the Delhi and Hanford soils. Although we were not able to document the reason why the redistribution flow in this soil was stable, it may be due to the rapid decline to a low flow rate during redistribution, or to the soil's large percentage of gravel and stones. Its behavior was similar to the stable profile reported by Flury et al. [1994] for a dye trace experiment conducted in a coarse-textured Les Barges 


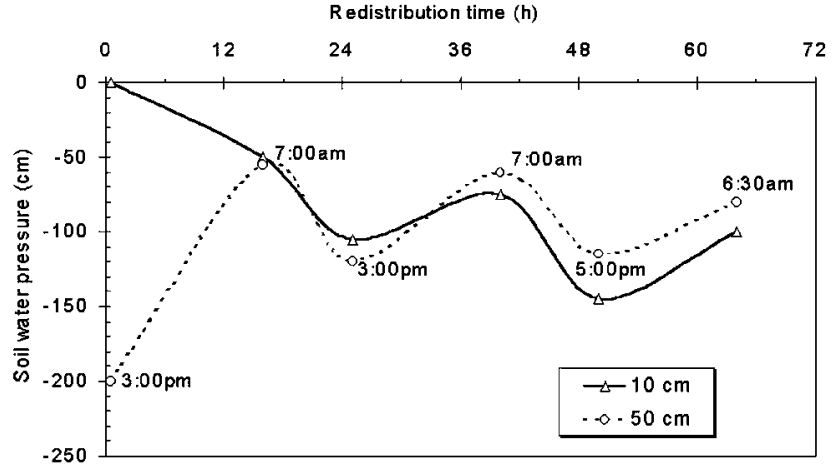

(a) Exp. 17: Delhi sand

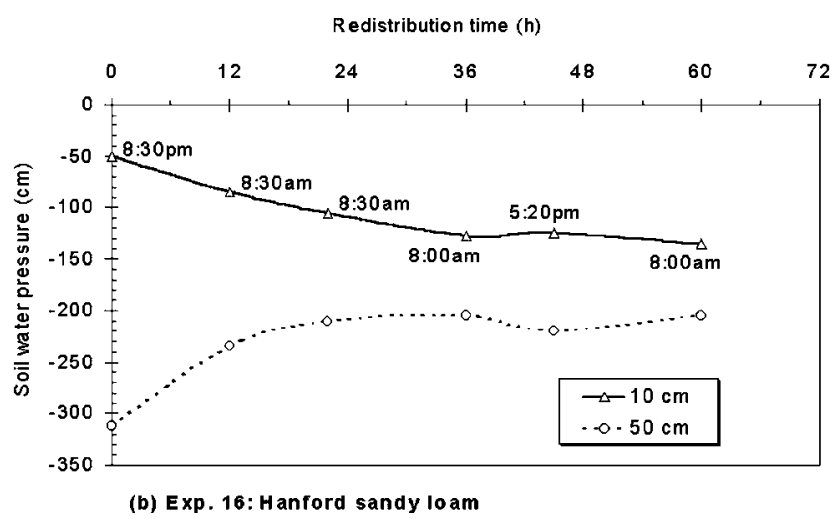

Figure 10. Changes of soil matric potential with the time of redistribution, measured at 10 and $50 \mathrm{~cm}$ below the plot surface.

sandy loam. Our results and theirs suggest that textural classification alone is not sufficient to diagnose the tendency for preferential flow.

[39] The other two soils exhibited preferential flow that commenced after infiltration stopped. The tortuosity of the wetting front increased for a period of time following the start of redistribution, and then decreased, indicating that capillary diffusion was smoothing out the front. Finger diameters were comparable in the two soils, and consistent with predictions from stability theory. The mean finger length was substantially larger in the Delhi sand than in the Hanford sandy loam, consistent with the former soil's lower water retention.

[40] Acknowledgments. The research was supported by research grant IS-2859-97 from BARD, the US-Israel Binational Agricultural Research and Development Fund.

\section{References}

Chuoke, R. L., P. van Meurs, and C. van der Poel, The instability of slow, immiscible, viscous liquid-liquid displacements in permeable media, Trans. Am. Inst. Min. Eng., 216, 188-194, 1959.

Diment, G. A., and K. K. Watson, Stability analysis of water movement in unsaturated porous materials: 3. Experimental studies, Water Resour. Res., 21, 979-984, 1985 .

Flury, M., Experimental evidence of transport of pesticides through field soils-A review, J. Environ. Qual., 25, 25-45, 1996.

Flury, M., H. Fluhler, W. A. Jury, and J. Leuenberger, Susceptibility of soils to preferential flow: A field study, Water Resour. Res., 30, 1945-1954, 1994.

Geiger, S. L., and D. S. Durnford, Infiltration in homogeneous sands and a mechanistic model of unstable flow., Soil Sci. Soc. Am. J., 64, 460-469, 2000 .
Ghodrati, M., F. F. Ernst, and W. A. Jury, Automated spray system for application of solutes to small field plots, Soil Sci. Soc. Am. J., 54 , $287-290,1990$

Ghodrati, M., and W. A. Jury, A field study of the effects of soil structure and irrigation method on preferential flow of pesticides in unsaturated soil, J. Contam. Hydrol., 11, 101-125, 1992.

Glass, R. J., and M. J. Nicholl, Physics of gravity fingering of immiscible fluids within porous media: an overview of current understanding and selected complicating factors, Geoderma, 70, 133-164, 1996.

Glass, R. J., T. S. Steenhuis, and J. Y. Parlange, Wetting front instability as a rapid and far-reaching hydrologic process in the vadose zone, J. Contam. Hydrol., 3, 207-226, 1988.

Glass, R. J., J. Y. Parlange, and T. S. Steenhuis, Wetting front instability: 1. Theoretical discussion and dimensional analysis, Water Resour. Res., 25, 1187-1194, 1989a.

Glass, R. J., T. S. Steenhuis, and J. Y. Parlange, Wetting front instability: 2. Experimental determination of relationships between system parameters and two dimensional unstable flow field behavior in initially dry porous media, Water Resour. Res., 25, 1195-1207, 1989b.

Glass, R. J., T. S. Steenhuis, and J. Y. Parlange, Mechanism for finger persistence in homogeneous, unsaturated, porous media: Theory and verification, Soil Sci., 148, 60-70, 1989c.

Hendrickx, J. M. H., L. W. Dekker, and O. H. Boersma, Unstable wetting fronts in water repellent field soils, J. Environ. Qual., 22, 109-118, 1993.

Hill, D. E., and J.-Y. Parlange, Wetting front instability in layered soils, Soil Sci. Soc. Am. Proc., 36, 697-702, 1972.

Jury, W. A., and H. Flühler, Transport of chemicals through soil: Mechanism, models, and field applications, Adv. Agron., 47, 141-201, 1992.

Jury, W. A., H. Elabd, and M. Resketo, Field study of napropamide through unsaturated soil, Water Resour. Res., 21, 749-755, 1986.

Klute, A., (Ed.), Methods of Soil Analysis, part 1, Physical and Mineralogical Methods, 2nd ed., Am. Soc. of Agron., Madison, Wis., 1986.

Kung, K. J. S., Preferential flow in a sandy vadose zone, 1. Field observations, Geoderma, 46, 51-58, 1990.

Nicholl, M. J., R. J. Glass, and S. W. Wheatcraft, Gravity-driven infiltration instability in initially dry non-horizontal fractures, Water Resour. Res. 30, 2546-2553, 1994.

Parlange, J. Y., and D. E. Hill, Theoretical analysis of wetting front instability in soils, Soil Sci., 122, 236-239, 1976.

Philip, J. R., Stability analysis of infiltration, Soil Sci. Soc. Am. Proc., 39, $1042-1049,1975$.

Raats, P. A. C., Unstable wetting fronts in uniform and non-uniform soils, Soil Sci. Soc. Am. Proc., 37, 681-685, 1973.

Ritsema, C. J., L. W. Dekker, J. M. H. Hendrickx, and W. Hamminga, Preferential flow mechanism in a water repellent sandy soil, Water Resour. Res., 29, 2183-2193, 1993.

Ritsema, C. J., T. S. Steenhuis, J. Y. Parlange, and L. W. Dekker, Predicted and observed finger diameters in field soils, Geoderma, 70, 185-196, 1996.

Rooij, G. H., and H. Cho, Modeling solute leaching during fingered flow by integrating and expanding various theoretical and empirical concepts, Hydrol. Sci., 44, 447-465, 1999.

Saffman, P. G., and S. G. Taylor, The penetration of fluid into a porous medium or Hele-Shaw cell containing a more viscous liquid, Proc. $R$. Soc. London, Ser. A., 245, 312-329, 1958.

Selker, J. S., T. S. Steenhuis, and J. Y. Parlange, Wetting front instability in homogeneous sandy soils under continuous infiltration, Soil Sci. Soc. Am. J., 56, 1346-1350, 1992

Si, B., R. G. Kachanoski, F. Zhang, G. W. Parkin, and D. E. Elrick, Measurement of hydraulic properties during constant flux infiltration: Field average, Soil Sci. Soc. Am. J., 63, 793-799, 1999.

Starr, J. L., H. C. DeRoo, C. R. Frink, and J.-Y. Parlange, Leaching characteristics of a layered field soil, Soil Sci. Soc. Am. J., 42, 386-391, 1978.

Starr, J. L., J.-Y. Parlange, and C. R. Frink, Water and chloride movement through a layered field soil, Soil Sci. Soc. Am. J., 50, 1384-1390, 1986

Su, G. W., J. T. Geller, K. Pruess, and F. Wen, Experimental studies of water seepage and intermitent flow in unsaturated, rough-walled fractures, Water Resour. Res., 35, 1019-1037, 1999.

Tamai, N., T. Asaeda, and C. G. Jeevaraj, Fingering in two-dimensional, homogeneous, unsaturated porous media, Soil Sci., 144, 107-112, 1987.

Van Ommen, H. C., L. W. Dekker, R. Dijksma, J. Hulsof, and W. H. van der Molen, A new technique for evaluating the presence of preferential 
flow paths in nonstructured soils, Soil Sci. Soc. Am. J., 52, 1192-1193, 1988.

Wang, Z., J. Feyen, M. T. van Genuchten, and D. R. Nielsen, Air entrapment effects on infiltration rate and flow instability, Water Resour. Res., 34, 213-222, 1998a.

Wang, Z., J. Feyen, and C. J. Ritsema, Susceptibility and predictability of conditions for preferential flow, Water Resour. Res., 34, 2169-2182, 1998 b.

Wang, Z., J. Feyen, and D. E. Elrick, Prediction of fingering in porous media, Water Resour. Res., 34, 2183-2190, 1998c.

Wang, Z., J. H. Lu, L. Wu, T. Harter, and W. A. Jury, Visualizing preferential flow paths using ammonium carbonate and a $\mathrm{pH}$-indicator, Soil Sci. Soc. Am. J., 66, 347-351, 2002.
Yao, T.-M., and J. M. H. Hendrickx, Stability of wetting fronts in dry homogeneous soils under low infiltration rates, Soil Sci. Soc. Am. J., 60, 20-28, 1996.

T. Harter, Department of Land, Air, and Water Resources, University of California, Davis, CA 95616, USA. (thharter@ucdavis.edu)

W. A. Jury, J. Lu, and L. Wu, Department of Environmental Sciences, University of California, Riverside, CA 92521, USA. (wajury@mail.ucr. edu; jianh@mail.ucr.edu; laowu@mail.ucr.edu)

Z. Wang, Department of Earth and Environmental Sciences, California State University, Fresno, CA 93740, USA. (zwang@csufresno.edu) 


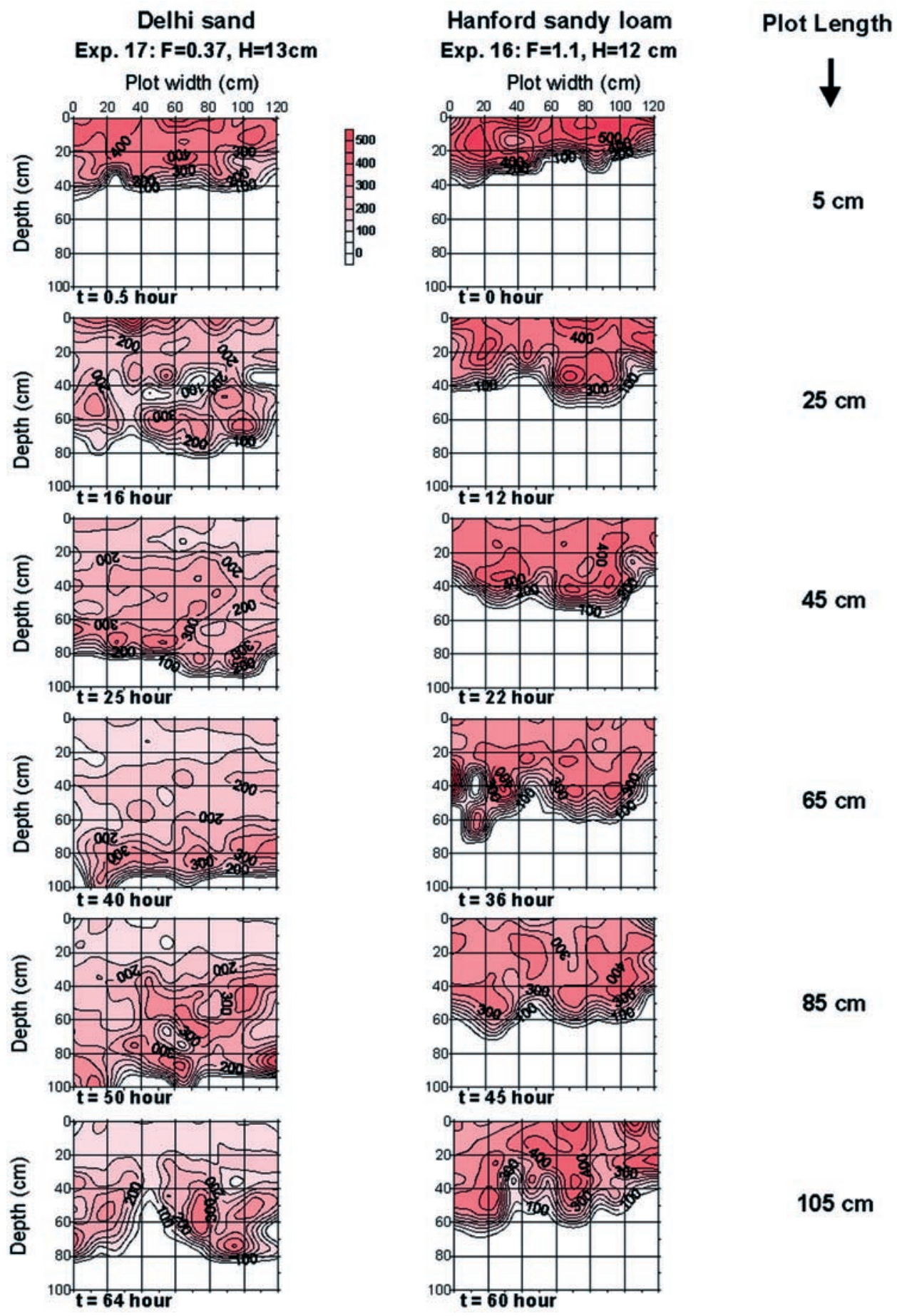

Figure 8. Redistribution of bromide concentration $(\mathrm{mg} / \mathrm{L})$ with time and space. 